LAWRENCE LIVERMORE N A T IO N A L LABORATORY

The role of Hydrogen and Creep in Intergranular Stress Corrosion Cracking of Alloy 600 and Alloy 690 in PWR Primary Water Environments \# a Review

Raul B. Rebak, Fred H. Hua

August 2, 2004

Environment Induced Cracking of Metals - 2 Banff, Canada September 19, 2004 through September 23, 2004 
This document was prepared as an account of work sponsored by an agency of the United States Government. Neither the United States Government nor the University of California nor any of their employees, makes any warranty, express or implied, or assumes any legal liability or responsibility for the accuracy, completeness, or usefulness of any information, apparatus, product, or process disclosed, or represents that its use would not infringe privately owned rights. Reference herein to any specific commercial product, process, or service by trade name, trademark, manufacturer, or otherwise, does not necessarily constitute or imply its endorsement, recommendation, or favoring by the United States Government or the University of California. The views and opinions of authors expressed herein do not necessarily state or reflect those of the United States Government or the University of California, and shall not be used for advertising or product endorsement purposes.

This work was performed under the auspices of the U.S. Department of Energy by the University of California, Lawrence Livermore National Laboratory under Contract No. W-7405-Eng-48. 
Article to be published by Elsevier as proceedings of the Second International Conference on EnvironmentInduced Cracking of Metals (EICM-2) 19-23 September 2004, Banff, Alberta, Canada

\title{
The role of hydrogen and creep in intergranular stress corrosion cracking of Alloy 600 and Alloy 690 in PWR primary water environments - a review
}

\author{
Fred H. Hua a and Raúl B. Rebak ${ }^{\mathrm{b}}$ \\ ${ }^{a}$ Bechtel SAIC Company, LLC, 1180 Town Center Drive, Las Vegas, NV 89144 \\ ${ }^{\mathrm{b}}$ Lawrence Livermore National Laboratory, 7000 East Ave, MS 631, Livermore CA 94550
}

\begin{abstract}
Intergranular attack (IGA) and intergranular stress corrosion cracking (IGSCC) of Alloy 600 in PWR steam generator environment has been extensively studied for over 30 years without rendering a clear understanding of the essential mechanisms. The lack of understanding of the IGSCC mechanism is due to a complex interaction of numerous variables such as microstructure, thermomechanical processing, strain rate, water chemistry and electrochemical potential. Hydrogen plays an important role in all these variables. The complexity, however, significantly hinders a clearer and more fundamental understanding of the mechanism of hydrogen in enhancing intergranular cracking via whatever mechanism. In this work, an attempt is made to review the role of hydrogen based on the current understanding of grain boundary structure and chemistry and intergranular fracture of nickel alloys, effect of hydrogen on electrochemical behavior of Alloy 600 and Alloy 690 (e.g. the passive film stability, polarization behavior and open-circuit potential) and effect of hydrogen on PWSCC behavior of Alloy 600 and Alloy 690. Mechanistic studies on the PWSCC are briefly reviewed. It is concluded that further studies on the role of hydrogen on intergranular cracking in both inert and primary side environments are needed. These studies should focus on the correlation of the results obtained at different laboratories by different methods on materials with different metallurgical and chemical parameters.
\end{abstract}

Keywords: PWR, PWSCC, hydrogen, creep, grain boundary.

\section{Introduction}

Intergranular attack (IGA) and intergranular stress corrosion cracking (IGSCC) of Alloy 600 in PWR steam generator environment has been extensively studied for over 30 years without rendering a clear understanding of the essential mechanisms [1]. The 
lack of understanding of the IGSCC mechanism is due to a complex interaction of numerous variables such as microstructure, thermomechanical processing, strain rate, water chemistry and electrochemical potential [1]. As far as the materials are concerned, most studies have been conducted with commercial alloys, which not only had heat-to-heat differences in composition but also experienced different thermomechanical histories. Among many metallurgical and chemical variables that may influence the behavior of grain boundaries, the grain boundary precipitation, the segregation of impurities to grain boundary, the depletion of chromium near the grain boundary and the oxide film stability have received extensive studies. The complexity significantly hinders a clearer and more fundamental understanding of the mechanism of hydrogen in enhancing intergranular cracking via whichever mechanism. Further studies on the role of hydrogen on intergranular cracking in both inert and primary side environments are needed and should focus on the correlation of the results obtained at different laboratories by different methods on materials with different metallurgical and chemical parameters. This review is focused on the role of hydrogen and creep in assisting intergranular stress corrosion cracking of Alloy 600 and Alloy 690 in nuclear steam generator primary side environments. A comprehensive review was recently published on the different submodes of stress corrosion cracking and the influencing variables from the secondary side [2].

\section{Grain boundary structure and chemistry of relevant nickel alloys}

Although the chemical composition of Alloy 690 does not differ significantly from that of Alloy 600, the resulting microstructure and IGA behavior can be very different $[3,4]$. For instance, Angeliu and Was showed that Alloy 600 type materials exhibited $\mathrm{M}_{7} \mathrm{C}_{3}$ on the grain boundary and $\mathrm{M}_{7} \mathrm{C}_{3}$ and $\mathrm{M}_{23} \mathrm{C}_{6}$ intergranularly, while Alloy 690 type of materials only exhibited $\mathrm{M}_{23} \mathrm{C}_{6}$ precipitation [3]. It is also reported that the Alloy 690 type of materials exhibited more Cr depletion than Alloy 600 type on an absolute scale but less $\mathrm{Cr}$ depletion when the comparison was relatively made (e.g. shown by percentage of $\mathrm{Cr}$ depletion). This is consistent with the thermodynamic calculation, which showed that less severe $\mathrm{Cr}$ depletion should be expected with precipitation of $\mathrm{Cr}_{23} \mathrm{C}_{6}$ than with $\mathrm{Cr}_{7} \mathrm{C}_{3}$ [5].

\subsection{The role of intergranular carbide precipitations}

Bruemmer and Henager assumed that grain boundary carbide precipitation acts as low energy dislocation sources, producing more homogeneous plastic deformation and modifying the local stress state [6]. The presence of a semi-continuous array of intergranular carbides may continuously blunt the crack tip and reduce the SCC crack propagation. Hertzberg and Was separated the effect of carbon in solution from the effect of carbon present as grain boundary carbides and demonstrated better resistance to IGSCC for materials with grain boundary carbides than with carbon in solution [7].

\subsection{Effect of grain size}

It has been found that coarse-grained Alloy $600(<$ ASTM 6) is less susceptible to IGSCC in high temperature water as compared to fine-grained alloys (>ASTM 8) $[8,9$, 10]. Sung and Was found IG of a simulated Alloy 600 in $360^{\circ} \mathrm{C}$ high purity water was 
dominant for small grain sized samples $(30 \mu \mathrm{m})$ over large grain-sized samples $(130$ $\mu \mathrm{m})[11]$. The effect of small grain size was found to enhance diffusional creep processes and decrease grain boundary segregation of impurities due to a larger grain boundary area per unit volume [12]. The effect of hydrogen on cracking of simulated Alloy 600 materials, however, was found controversial [11, 13, 14]. For small grainsized materials $(30 \mu \mathrm{m})$, increasing hydrogen overpressure from $100 \mathrm{KPa}$ to $200 \mathrm{KPa}$ increased the $\%$ of IG by $61 \%$, while for large grain-sized materials (130 micro $\mathrm{m})$, the $\%$ of IG decreased from $13.9 \%$ to $6.1 \%$. On the other hand, Symons' data for hydrogen-charged and uncharged Alloy 690 specimens in air showed that aging (TT) after solution annealing (MA) increased the grain size and grain boundary carbide precipitation and, therefore, increased the propensity of intergranular cracking [15].

Hydrogen is more effective in embrittling the material when the carbide size and carbide coverage increased. Aging Alloy 690 increased grain boundary carbide size and the extent of grain boundary $\mathrm{M}_{23} \mathrm{C}_{6}$ carbide coverage. Therefore, aging increased the degree of hydrogen embrittlement of the alloy [15]. The results from fracture toughness testing showed that $\mathrm{J}_{\mathrm{IC}}$ decreased by hydrogen charging from about $480 \mathrm{~kJ} / \mathrm{m}^{2}$ for uncharged specimens to about $210 \mathrm{~kJ} / \mathrm{m}^{2}$ for solution annealed materials. For solution annealed followed by aged materials, $J_{I C}$ was further reduced to $90 \mathrm{~kJ} / \mathrm{m}^{2}$ [15]. The morphological study showed that as the hydrogen content increased, the fracture morphology changed from mainly transgranular ductile fracture for uncharged MA materials to mainly intergranular brittle cracking for TT charged materials [15].

The two contributing factors explaining the fact that the increased grain size is responsible for increased hydrogen embrittlement are (i) increased grain size increases the local stress at the particles, which would result in a lower strain necessary for decohere the grain boundary/carbide interface, as proposed by Goods and Brown [16]; and (ii) hydrogen is preferentially trapped at the carbide/matrix interface, reducing the strength of the interface more than at the matrix/matrix interface, as proposed by Young and Scully [17].

\subsection{Effect of carbon content}

Sung and Was observed that addition of $300 \mathrm{ppm}$ carbon in solution to a controlled purity $\mathrm{Ni}-16 \mathrm{Cr}-9 \mathrm{Fe}$ alloy significantly increased the strength and resistance to IGSCC in $360^{\circ} \mathrm{C}$ high purity water [11].

The main effect of carbon doping to $\mathrm{Ni}-16 \mathrm{Cr}-9 \mathrm{Fe}$ type and $\mathrm{Ni}-30 \mathrm{Cr}-9 \mathrm{Fe}$ type nickel alloys was found to enhance the formation of the corrosion products, in particular the $\mathrm{Ni}(\mathrm{OH})_{2}$. The carbon-free Alloy 600 was found to have a $\mathrm{Cr}_{2} \mathrm{O}_{3}$-rich film. Doping carbon increased the film thickness from $38 \mathrm{~nm}$ to $281 \mathrm{~nm}$ with a large amount of increase in $\mathrm{Ni}(\mathrm{OH})_{2}$. In the case of Alloy 690, doping carbon increased the film thickness slightly from $46 \mathrm{~nm}$ to $58 \mathrm{~nm}$ with somewhat more $\mathrm{Cr}$ and $\mathrm{Fe}$ found in the film [18]. 


\subsection{Effect of chromium content}

Increased chromium content up to about 19\% in Alloy 600 and Alloy 750 did not appreciably change their microstructure, such as the grain size and distribution of interand intragranular carbide precipitation, in hydrogenated primary water at $350 \sim 360^{\circ} \mathrm{C}$ and in steam at $400^{\circ} \mathrm{C}$ [19]. The mechanical properties were not significantly changed by the increased chromium content either. However, the increased chromium content significantly improved the resistance to intergranular SCC in hydrogenated primary water. On the other hand, the increased $\mathrm{Cr}$ content did not significantly improve the SCC resistance to caustic SCC [19]. It was concluded that the increased resistance to SCC of Alloy 600 by increasing Cr content could not be attributed to the changes in microstructure but to the improvement in passive film [19].

Noel et al, by using chronoamperometric method, showed that the increased $\mathrm{Cr}$ content only slightly improved the repassivation ability of the passive film of nickel alloys in primary water and the improvement seemed to be too small to explain the significant improvement in PWSCC resistance of Alloy 690 over Alloy 600 [20]. Using CERT and constant load methods[18], Angeliu et al [18] showed that in both argon and high purity hydrogenated water $\left(18 \mathrm{M} \Omega\right.$ and $16 \mathrm{cc} / \mathrm{kg}$ hydrogen, $\left.0.1 \mathrm{MPa}, \mathrm{O}_{2}<10 \mathrm{ppb}\right)$ the increasing $\mathrm{Cr}$ from 5 to 16 to $30 \mathrm{wt} \%$ decreased the \% of IG fracture. As $\mathrm{Cr}$ content increased, the steady-state creep rate decreased. Extrapolation of the incomplete curves revealed several orders of magnitude difference in creep rate at same stress level due to chromium alone. As demonstrated by Angeliu et al on controlled purity $\mathrm{N}-\mathrm{Cr}-\mathrm{Fe}$ low carbon alloys [21], the effect of chromium is to decrease the creep rate at $360^{\circ} \mathrm{C}$ as a result of solid solution strengthening. The soluble carbon has a similar but much stronger effect. Increased $\mathrm{Cr}$ content also increased the thickness of the surface film as observed by Angeliu et al [18]. Increasing $\mathrm{Cr}$ content from 16 to $30 \mathrm{wt} \%$ increased the thickness of the film from $46 \mathrm{~nm}$ to $58 \mathrm{~nm}$ with an enrichment in $\mathrm{Cr}_{2} \mathrm{O}_{3}$. Note that the role of carbon in thickening surface film is to enrich $\mathrm{Ni}(\mathrm{OH})_{2}$, rather than $\mathrm{Cr}_{2} \mathrm{O}_{3}$ [18].

\subsection{Effect of chromium depletion}

The phenomenon of chromium depletion along the grain boundary after grain boundary carbide precipitation is well known [3, 22, 23, 24]. Norring et al attempted to correlate the grain boundary microstructure and chemistry with IGSCC of Alloys 600 and 690 [24]. Six different Alloy 600 and Alloy 690 tube materials were tested in hydrogenated ( $\left.5.9 \mathrm{kPa}, 50 \mathrm{ml} \mathrm{H}_{2} / \mathrm{kg} \mathrm{H}_{2} \mathrm{O}\right) 365^{\circ} \mathrm{C}$ deaerated $\left(\mathrm{O}_{2}<5 \mathrm{ppb}\right)$ water by using RUB method. All Alloy 690 specimens were crack-free even after extremely long exposure time (>23,000 hours), while most Alloy 600 specimens showed IGSCC after 12, 000 hours or less. TEM, EDX and Atom Probe results showed that all Alloy 690 exhibited intergranular and intragranular carbide precipitation of the type M23C6 that were more or less globular, while The $\mathrm{M}_{7} \mathrm{C}_{3}$ type of carbide precipitation was predominant in Alloy 600 in all conditions. Chromium depletion was observed at the grain boundaries both in Alloy 600 and Alloy 690. In Alloy 690, the Cr-depletion was more pronounced after TT at $715^{\circ} \mathrm{C}(\sim 6 \%)$ than in MA condition ( 3\%). Cr-depletion was found in Alloy 600 with $\mathrm{M}_{23} \mathrm{C}_{7}$ type of grain boundary precipitation. In Alloy 600 only with $\mathrm{M}_{7} \mathrm{C}_{3}$ type grain boundary precipitation, no $\mathrm{Cr}$-depletion was observed. 


\subsection{Effect of segregation of impurities}

More grain boundary carbides seemed to be detrimental to IGSCC as suggested in the rising load tests on X-750 in $93^{\circ} \mathrm{C}$ water with cathodic charging performed by Miglin and Domain [25] where it was found that the cracking propensity of HTH treated samples was reversed, suggesting that the role of grain boundary segregation should be considered.While the IGSCC of Alloy X-750 has been attributed to grain boundary P segregation [26], Airey found that P present at grain boundary of Alloy 600 following thermal treatment provided the most resistant structure [27]. Cornet et al showed that for solution-annealed samples of high purity $\mathrm{Ni}-\mathrm{Cr}-\mathrm{Fe}$, the addition of $\mathrm{P}$ and $\mathrm{C}$ tend to decrease the degree of IG cracking during cathodic charging [28], further supported by tension tests of precharged samples of high purity Ni-Cr Fe doped with P and heattreated so as to segregate $\mathrm{P}$ to the grain boundary [4]. Was was able to show that the ultimate tensile strength increased monotonically with increasing $\mathrm{P}$ at the grain boundary [4]. On the contrary, Caceres et al. found that among P, Si and B added to Alloy 600 , only $\mathrm{P}$ segregated to grain boundary after thermal treatment at $704^{\circ} \mathrm{C}$ for 16 hours and promoted IG fracture when $\mathrm{M}_{7} \mathrm{C}_{3}$ grain boundary carbides were present [29, 30].

Sung and Was comprehensively studied the role of grain boundary chemistry in pure water intergranular stress corrosion cracking by using controlled purity $\mathrm{Ni}-16 \mathrm{Cr}-9 \mathrm{Fe}$ alloys [11] by performing SCC tests on a series of controlled purity nickel alloys in $360^{\circ} \mathrm{C}$ high purity water with oxygen $<10 \mathrm{ppb}$ and a conductivity of 0.056 micro S/cm and hydrogen overpressure of $100 \mathrm{KPa}$ and $200 \mathrm{KPa}$ with a strain rate of $4.2 \times 10^{-6}$ $\mathrm{mm} / \mathrm{sec}$. The authors concluded that high purity alloys showed inherent IG cracking in both high purity water and $\mathrm{Ar}$ at $360^{\circ} \mathrm{C}$, while alloys containing impurities (carbon, boron and phosphorous) retarded IG cracking possibly due to the lowered diffusivity of metal caused by impurity segregation to grain boundary. The chromium depletion at grain boundary was found not to promote IG cracking.

Airey [27] suggested that the beneficial effect of thermal treatment of Alloy 600 at $700^{\circ} \mathrm{C}$ for 15 hours after MA appeared to be due to the grain boundary segregation of boron and phosphorous, which retarded grain boundary diffusivity at $300^{\circ} \sim 400^{\circ} \mathrm{C}$, while low IGSCC susceptibility of Alloy 600 mill annealed at higher temperature (> $1050^{\circ} \mathrm{C}$ ) was attributed to a high carbon content in solution and larger grain size [31].

In Symons' work on hydrogen effect on mechanical properties of Alloy 690, the author found that the segregation of sulfur was independent of heat treatment [15]. After MA, the grain boundary phosphorous segregation was slightly lower for lower P containing material $(0.006 \mathrm{wt} \%)$ than higher P containing material $(0.013 \mathrm{wt} \%)$. However, After TT, the grain boundary $\mathrm{P}$ segregation of the low $\mathrm{P}$ containing alloy increased to the same level as the high P containing alloy's. In high P containing (about $0.013 \mathrm{wt} \%$ ) material, the heat treatment did not affect the grain boundary segregation of P. On the other hand, Stiller et al observed only small amount of grain boundary P segregation [32]. 


\subsection{Effect of special grain boundary $(S G B)$}

The coincident site lattice boundary (CSLB) has been shown to affect high temperature intergranular oxidation [33] and grain boundary carbide density [34]. Cheung et al showed that the coincident site lattice boundary (CSLB) morphology influenced the IGSCC behavior of Alloy 600 [35]. A decrease in total fraction of IGSCC in alloys with enhanced CSLB levels has been observed [36]. The creep rate could be decreased due to the presence of a high fraction of CSLBs decreased the creep rate [37]. It has been demonstrated that alloys with CSLBs have a greater (2 14 higher) resistance to IGSCC than the high angle boundariesin all samples tested with the greatest benefit at low strain $(<15 \%)$ [35]. Cheung et al also showed that grain boundary carbide precipitation is affected by grain boundary energy and grain misorientation angle [35].

\section{Effect of Hydrogen on Electrochemical Behavior of Alloy 600 and Alloy 690}

\subsection{Effect of hydrogen on oxide film stability}

A maximum susceptibility to PWSCC generally seems to exist as a function of hydrogen partial pressure and is near the $\mathrm{Ni} / \mathrm{NiO}$ equilibrium at the various temperatures. The primary role of hydrogen partial pressure is to modify the surface oxide properties (thickness, composition, protectiveness etc). However, the increase in susceptibility of alloy 600 under cathodic polarization suggested that other hydrogen related processes must be involved to explain the maximum susceptibility of PWSCC [38]. The effect of hydrogen on oxide film stability is not well understood.

\subsection{Effect of hydrogen overpressure on polarization behavior}

Totuska and Szklarska-Smialowska conducted SSRT studied on Alloy 600 in $0.01 \mathrm{M}$ boron and $0.001 \mathrm{M}$ lithium high temperature water with 0.005 and $0.1 \mathrm{MPa}$ hydrogen overpressure under controlled potentials [39]. It was found that the anodic current density was higher under $0.1 \mathrm{MPa}$ than under $0.005 \mathrm{MPa}$. The open-circuit potential was about $60 \mathrm{mV}$ more negative for $0.1 \mathrm{MPa}$ than that in $0.005 \mathrm{MPa}$. The AC Impedance results showed that the charge transfer resistance, $R_{t}$, was found to be smaller under 0.1 MPa than that under $0.005 \mathrm{MPa}$, regardless of the potential applied ($300 \mathrm{mV}$ (Ecorr), $\mathrm{E}_{\text {corr }}$ and $+300 \mathrm{mV}_{\text {(Ecorr). }}$. Both the fact that above $-0.835 \mathrm{~V}_{\text {(SHE) }}$ no IGSCC occurred and the fact that IGSCC only occurred when there was significant amount of hydrogen in the alloy suggested that hydrogen was responsible for the IGSCC.

Vaillant et al conducted electrochemical measurement for Alloy 600 and Alloy 690 in $360^{\circ} \mathrm{C}$ hydrogenated primary water $(2 \mathrm{ppm} \mathrm{Li}$ and $1000 \mathrm{ppm} \mathrm{B})$ [40]. It was found that for hydrogen pressure from 0.02 to 0.12 bar ( 3 to $23 \mathrm{cc} \mathrm{H}_{2} / \mathrm{kg} \mathrm{H} \mathrm{H}_{2} \mathrm{O}$ ), the corrosion potentials of Alloy 600 and Alloy 690 were similar to the redox potential on a platinum wire at $360^{\circ} \mathrm{C}$ under hydrogen pressure from 0.02 to $2.9 \mathrm{bar}(3$ to $500 \mathrm{cc} / \mathrm{kg}$ ), i.e. -0.95 $\sim-1.07 \mathrm{~V}_{\text {(SHE) }}$, the equilibrium potential of $\mathrm{H}^{+} / \mathrm{H}_{2}$. On the potentiokinetic curves, the first peak corresponding to $\mathrm{Ni} \rightarrow \mathrm{NiO}$ and $\mathrm{Fe}_{3} \mathrm{O}_{4} \rightarrow \mathrm{Fe}_{2} \mathrm{O}_{3}$ and a passive region (150 $\mathrm{mV}$ ) were about two times lower for Alloy 690 than for Alloy 600. The potentials for the second peak corresponding to $\mathrm{Cr}_{2} \mathrm{O}_{3} \rightarrow \mathrm{CrO}_{4}{ }^{2-}$ and $\mathrm{NiO} \rightarrow \mathrm{Ni}_{3} \mathrm{O}_{4}$ were found to be 
higher for Alloy 690 than for Alloy 600. When the hydrogen pressure was increased, the current densities increased due to the oxidation current of $\mathrm{H}_{2}$ and the peaks were less distinct. By current transient method, the authors found that increasing hydrogen pressure from 0.02 to 0.12 bar increased the repassivation kinetics by a factor of 2 . The repassivation kinetics on Alloy 690 was slightly higher than that on Alloy 600.

\subsection{Effect of hydrogen on open-circuit potential}

Sung and Was monitored the electrochemical potential of the $\mathrm{Ni}-16 \mathrm{Cr}-9 \mathrm{Fe}$ samples with different grain boundary chemistry in $360^{\circ} \mathrm{C}$ high purity water [11]. No significant difference in electrochemical potential due to different impurities was observed. Increasing hydrogen overpressure from $100 \mathrm{KPa}$ to $200 \mathrm{KPa}$ changed the potential from $60 \mathrm{mV}$ to $72 \mathrm{mV}$ as verses a Pt reference electrode. Totuska et al reported that in $350^{\circ} \mathrm{C}$ simulated primary water with $100 \mathrm{KPa}$ hydrogen overpressure, the potential of a commercial Alloy 600 was ranging from $-22 \mathrm{mV}$ to $14 \mathrm{mV}$ as measured by a $\mathrm{Pt}$ reference electrode [41].

\section{Effect of hydrogen on PWSCC behavior of Alloy 600 and Alloy 690}

Uniaxial tensile and compact tension (for $\mathrm{J}_{\mathrm{IC}}$ ) tests on uncharged and hydrogen-charged MA and TT Alloy 690 specimens showed that hydrogen had only a slight effect on the yield strength of the materials but has a significant effect on other mechanical properties such as reduction in area at failure [15]. Hydrogen charging significantly decreased the reduction in area.

It has been shown that hydrogen can accelerate or induce IGSCC in Alloy 600 [10, 39 $42,43,44]$. Alloy 600 containing a high density of intergranular carbides were less susceptible to IGSCC in hydrogen-containing water than those with fewer grain boundary carbides [10, 45, 46]. On the other hand, it has been reported that in Alloy 690 , hydrogen contents of over $0.24 \mathrm{MPa}(3.8 \mathrm{ppm})$ in high purity high temperature water have failed to induce any IG cracking regardless of the distribution of carbides in the matrix or on the grain boundary [11].

Airey examined the effect of dissolved hydrogen on SCC of Alloy 600 tubes in $360^{\circ} \mathrm{C}$ water by RUB testing with and without the dissolved hydrogen content of $42 \mathrm{cc} / \mathrm{kg}$ by maintaining a hydrogen overpressure of 35 psig [47]. In presence of hydrogen, all MA materials were cracked within 1500 hours. $60 \%$ of MA materials cracked after 9000 hours without hydrogen. None of the TT materials were cracked in either hydrogencontained or non-hydrogen contained environments. In $360^{\circ} \mathrm{C}$ water and $400^{\circ} \mathrm{C}$ steam, an increase in hydrogen partial pressure from $6.9 \mathrm{KPa}(42 \mathrm{cc} / \mathrm{kg})$ to $34.5 \mathrm{KPa}(210$ $\mathrm{cc} / \mathrm{kg}$ ) decreased the time-to-failure by a factor of 6 for one heat of the materials [48]. Bandy and Van Rooyen tested nine heats of Alloy 600 in $365^{\circ} \mathrm{C}$ water with and without hydrogen. In the absence of hydrogen only $2 \%$ of the specimens cracked after 12 weeks of exposure whereas $83 \%$ of specimens cracked when the environment contained about $35 \mathrm{cc} / \mathrm{kg}$ hydrogen [49]. Not only hydrogen increased the number of crack but also increased the crack growth rate as evidenced by SSRT tests. The estimated crack growth rate in the presence of hydrogen was approximately $10^{-6} \mathrm{~mm} / \mathrm{s}$. 


\subsection{Hydrogen content in the specimens}

It was evident that a high hydrogen concentration did not suffice to cause cracking if no complex triaxial stress state or cold working zone is present.

Analysis of hydrogen contents in specimens exposed in high temperature water with different levels of hydrogen overpressure showed that in general the hydrogen content of the SSRT specimens increased with hydrogen partial pressure even in the unstrained portion of the specimens but in the strained portion hydrogen content is always much higher than that in unstrained portion of the specimens [43]. The hydrogen content in the specimens exposed for longer than 100 hours were found independent of the hydrogen overpressure applied. Totuska et al. concluded that (1) hydrogen is absorbed by the alloy not only from the water dissolved hydrogen gas but also from water molecules as well which probably occurs via their dissociative absorption on the alloy surface and (2) after 100 hours exposure, a steady-state is established between the $\mathrm{H}$ adsorbed on the surface and the $\mathrm{H}$ dissolved in the alloy [43]. A noticeable observation is that, despite the high hydrogen concentration in smooth SSRT specimens, no IGSCC was observed [43].

To differentiate the mechanisms by "pure" hydrogen embrittlement and by a combined effects of hydrogen, corrosion and plasticity, Noel et al performed fast strain rate CERT tests on Alloy 600 in $360^{\circ} \mathrm{C}$ primary water after open-circuit potential exposure for 100 hours or cathodic charging at $E_{c}=E_{\text {corr }}-320 \mathrm{mV}$ [20]. The strain rate was chosen in the range of from $10^{-3}$ to $6 \times 10^{-5} \mathrm{~s}^{-1}$, at which the authors believed that SCC could not occur but room temperature hydrogen embrittlement was possible. No reduction in elongation or cracking was observed. The post-test hydrogen analysis showed that no or little hydrogen was present in the pre-charged CERT specimens, while the hydrogen content in SSRT was higher at all potentials. The SSRT tests were also performed on Alloy 690 at $E_{\text {corr }}$ and $E_{\text {corr }}-320 \mathrm{mV}$. No effect of cathodic potential on Alloy 690 was observed [29. This is consistent with the results of Magnin et al [ 50] who measured the hydrogen content in the specimens of Alloy 600 (MA) after unstressed cathodic charging (100) and SSRT at $\mathrm{E}_{\text {corr }}$ (700 hours) and $\mathrm{E}_{\text {corr }}-320 \mathrm{mV}$ (400 hours). While the hydrogen content was found much higher in SSRT specimens than unstressed specimens, increasing cathodic polarization did not further increased the hydrogen content in the SSRT specimens.

Table 1 summarizes some of the results reported by different authors for their work done with different ways of hydrogen charging and different strain states of the specimens while charging.

\subsection{Effects of stress and strain states on hydrogen ingress}

Intergranular cracks primarily initiate and develop at locations where a complex state of high stress and strain exists $[10,1 \overline{5}$. 
Symons demonstrated the importance of a complicated stress state to hydrogen embrittlement in Alloy 690 [15]. While in tensile testing $38 \mathrm{ppm}$ hydrogen appeared to be sufficient to embrittle many grain boundaries and additional hydrogen only embrittle some of the remaining "stronger" grain boundaries, in fracture-toughness specimens, the $38 \mathrm{ppm}$ hydrogen caused almost $100 \%$ intergranular cracking for aged specimens due to the much higher hydrostatic stress in the compact tension specimen than in the tensile specimen. According to Symons, embrittlement due to hydrogen increases as the materials are aged to allow grain boundary carbide precipitation. Increased hydrogen at the carbide/matrix interface due to trapping and increased stress at the precipitation interface, which developed from strain incompatibility of the precipitate with the matrix. Increasing hydrostatic stress increases the tendency for intergranular cracking [15].

Table 1 The hydrogen content in specimens under various charging methods

\begin{tabular}{|c|c|c|c|c|}
\hline Materials & Specimen Type & Charging Method & $\begin{array}{l}\text { Hydrogen } \\
\text { Content, } \\
\text { ppm }\end{array}$ & Ref. \\
\hline \multirow[t]{4}{*}{ Alloy 600 (MA) } & Unstressed (as received) & $\begin{array}{l}\text { Cathodic charging for } \\
100 \text { hours }\end{array}$ & 2.9 & \multirow[t]{4}{*}{50} \\
\hline & $\begin{array}{l}\text { Unstressed } \\
\text { (electropolished) }\end{array}$ & $\begin{array}{l}\text { Cathodic charging for } \\
100 \text { hours }\end{array}$ & $2.9 \sim 6.2$ & \\
\hline & SSRT & SSRT for 700 hours & $7.9 \sim 12.7$ & \\
\hline & SSRT & $\begin{array}{l}\text { Cathodic charging at } \\
\text { Ecorr }-320 \mathrm{mV}\end{array}$ & $7.8 \sim 11.0$ & \\
\hline \multirow{6}{*}{$\begin{array}{l}\text { Alloy } 600(\mathrm{MA} \\
\text { or TT) }\end{array}$} & Unstressed (as received) & No charging & 2.4 & \multirow[t]{6}{*}{20} \\
\hline & $\operatorname{SSRT}\left(10^{-7} \mathrm{~s}^{-1}\right)$ & Ecorr & $7.9 \sim 12.7$ & \\
\hline & $\operatorname{SSRT}\left(10^{-7} \mathrm{~s}^{-1}\right)$ & $\begin{array}{l}\text { Cathodic charging at } \\
\text { Ecorr }-320 \mathrm{mV}\end{array}$ & $7.8 \sim 11.0$ & \\
\hline & CERT $\left(4 \times 10^{-4} \mathrm{~s}^{-1}\right)$ & $\begin{array}{l}\text { After Cathodic pre- } \\
\text { charging for } 100 \text { hours } \\
\text { ours }\end{array}$ & 2.9 & \\
\hline & $\begin{array}{l}\text { CERT }\left(10^{-3} \mathrm{~s}^{-1}\right) \text { (for } \\
\text { electropolished } \\
\text { samples) }\end{array}$ & $\begin{array}{l}\text { After cathodic pre- } \\
\text { charging for } 100 \text { hours }\end{array}$ & 6.2 & \\
\hline & $\begin{array}{l}\text { CERT }\left(6 \times 10^{-5} \mathrm{~s}^{-1}\right) \text { (for } \\
\text { electropolished } \\
\text { samples) }\end{array}$ & $\begin{array}{l}\text { After cathodic pre- } \\
\text { charging for } 100 \text { hours }\end{array}$ & 2.9 & \\
\hline \multirow[t]{2}{*}{ Alloy 690 (MA) } & \multirow[t]{2}{*}{ Uniaxial tensile and CT } & Gaseous, $13 \mathrm{MPa}$ & 38 & \multirow[t]{4}{*}{15} \\
\hline & & Gaseous, $34 \mathrm{MPa}$ & 59.5 & \\
\hline \multirow[t]{2}{*}{ Alloy $690(\mathrm{TT})$} & \multirow[t]{2}{*}{ Uniaxial tensile and CT } & Gaseous, $13 \mathrm{MPa}$ & 37.5 & \\
\hline & & Gaseous, $34 \mathrm{MPa}$ & 61 & \\
\hline Alloy 600 (MA) & $\begin{array}{l}\text { SSRT }\left(5 \times 10^{-7} \mathrm{~s}^{-1}\right) \text {, cold- } \\
\text { worked }\end{array}$ & $\begin{array}{l}0.005 \text { and } 0.1 \quad \mathrm{MPa} \\
\begin{array}{l}\text { overpressure } \\
\text { precharging }\end{array}\end{array}$ & 30 & 43 \\
\hline
\end{tabular}

Cox and Low experimentally showed that increasing the particle size or increasing hydrostatic stress of steel decreased the strain required to nucleate voids [51]. Goods and Brown [16] developed models to void formation. Their models predict that an increase in particle size would increase the local stress at the particles, resulting an 
easier decohesion of the grain boundary/particle (e.g. carbides) interface. Increasing the hydrostatic stress would increase the local stress as well and results in a lower strain for decohesion.

The enrichment of hydrogen has been quantitatively related to the increased hydrostatic stress as described by the following equation [52]:

$$
C_{H}=C_{H 0} \exp \left(\frac{\sigma_{H} \bar{V}}{R T}\right)
$$

where $\mathrm{C}_{\mathrm{H}}$ is the local hydrogen concentration, $\mathrm{C}_{\mathrm{H} 0}$ is the hydrogen concentration in the unstressed region, $\sigma_{\mathrm{H}}$ is the hydrostatic stress, $\mathrm{V}$ is the partial molar volume of hydrogen, R, the universal gas constant and T, the absolute temperature in Kelvin.

\subsection{Effect of cathodic polarization}

Noel et al compared the crack length and crack growth rates of Alloys 600 and 690 in argon and primary water by SSRT at $\mathrm{E}_{\text {corr }},-80 \mathrm{mV}$ and $-320 \mathrm{mV}$ (both versus $\mathrm{E}_{\text {corr }}$ )[20]. For Alloy 600 , the authors found that the maximum crack length was $70 \mu \mathrm{m}$ at $\mathrm{E}_{\text {corr }}$ and $400 \mu \mathrm{m}$ at cathodic polarization. The cathodic polarization at $-320 \mathrm{mV}$ increased the crack growth rate of Alloy 600 from $0.1 \mu \mathrm{m} / \mathrm{hr}$ at $-80 \mathrm{mV}$ to $1.0 \mu \mathrm{m} / \mathrm{h}$.

Magnin et al conducted interrupted CERT and constant load testing on Alloy 600 (MA) in $360^{\circ} \mathrm{C}$ primary water $(2 \mathrm{ppm} \mathrm{Li}+1000 \mathrm{ppm} \mathrm{B})$ with 0.13 bar hydrogen overpressure under different cathodic potential $\left(\mathrm{E}_{\text {corr }}\right.$ to $\left.\mathrm{E}_{\text {corr }}-320 \mathrm{mV}\right)$ [53]. After $3 \%$ of plastic straining, cracks were initiated under all cathodic potential conditions. No effect of cathodic potential was observed. However, when the crack growth rate was measured at a strain rate of $10^{-7} \mathrm{~s}^{-1}$, it was found that the CGR increased by a factor of $2 \sim 5$ when a cathodic potential was applied as compared to the crack growth rate at $\mathrm{E}_{\text {corr }}$. The crack growth rate reached a limit value close to $0.5 \mu \mathrm{m} / \mathrm{h}$ when the potential fell below $\mathrm{E}_{\text {corr }}$ $80 \mathrm{mV}$. Increasing the strain rate to $2.5 \times 10^{-7} \mathrm{~s}^{-1}$ (the rapid straining) increased the crack growth rate to $8 \sim 15$ time higher than the crack growth rate obtained at slow strain condition. Compared to $\mathrm{Ar}$ data, the elongation to failure at $\mathrm{E}_{\text {corr }}$ slightly decreased whereas all mechanical properties were strongly influenced by cathodic polarization. The crack depth was $70 \mu \mathrm{m}$ at $\mathrm{E}_{\text {corr }}$ and $400 \mu \mathrm{m}$ when a cathodic potential was applied. The crack growth rate was increased from $0.1 \mu \mathrm{m} / \mathrm{h}$ at $\mathrm{E}_{\text {corr }}$ to about 1.0 $\mu \mathrm{m} / \mathrm{h}$ at cathodic potential. However, the crack growth rate at $\mathrm{E}_{\text {corr }}-30 \mathrm{mV}, \mathrm{E}_{\text {corr }}-80$ $\mathrm{mV}$ and $\mathrm{E}_{\text {corr }}-320 \mathrm{mV}$ did not vary significantly.

Totuska and Szklarska-Smialowska conducted SSRT studies on Alloy 600 in $0.01 \mathrm{M}$ boron and $0.001 \mathrm{M}$ lithium high temperature water with 0.005 and $0.1 \mathrm{MPa}$ hydrogen overpressure under controlled potentials [39]. It was found that the IGSCC of Alloy 600 only occurred at potential more negative than a certain threshold value of potential depending on hydrogen overpressure. At $0.1 \mathrm{MPa}$ hydrogen overpressure, the threshold 
potential was $100 \mathrm{mV}$ more negative than $\mathrm{E}_{\text {corr }}$, which, converted to SHE, was about $0.835 \mathrm{~V}$ (sHE).

\section{Mechanistic studies on PWSCC}

In spite of numerous studies performed on the subject of primary water stress corrosion cracking of Alloys 600 and 690 during the past 30 years, the mechanism by which the cracking occurs is still a matter of debate. Historically, SCC has generally been explained either by the classical slip-step dissolution model or by hydrogen embrittlement mechanism. According to Noel et al [20], the classical SCC theories cannot account for all the phenomena observed in PWSCC of nickel alloys. Other hypothesis have been proposed to explain the recently observed experimental results. For example, Angeliu et al proposed that a brittle rupture occurs due to a localized modification of plasticity by interaction between corrosion and hydrogen [54]. Scott and Le Calvar proposed the internal oxidation mechanism [55]. Mechanisms involving creep damage have also been proposed $[56,57,58]$.

\subsection{Slip-Step Dissolution}

The slip-step dissolution model relates the crack advance to the local strain rate that exposes bare metal surface followed by dissolution of the metal. Any factors that enhance SCC are expected to enhance either the metal dissolution rate or strain rate. The application of slip-step dissolution mechanism to IG cracking of Alloy 600 in PWR water environments is questionable because IG cracking has been shown to be unaffected by chromium depletion [59] and higher solution conductivity [49]. Contrary to BWR experience, the susceptibility of Alloy 600 to IGSCC in PWR environments increases as the corrosion potential decreases, either by increasing the hydrogen content of the water or by decreasing the applied potential [13, 39, 43]. Moreover, the detrimental effect of hydrogen overpressure on SCC of Alloy 600 in primary water environments is not due to an increase in dissolution via a destabilization of the film as demonstrated by Noel et al [20]. Moreover, the cathodic polarization drastically increases the cracking [20]. Therefore, the dissolution mechanism seems not to be supported by the experimental observations.

\subsection{Hydrogen Embrittlement}

The conventional hydrogen embrittlement relies on several sub-processes where hydrogen ingresses into the metal surface and induces either a higher local stress or a lower lattice cohesion energy. Hydrogen may also locally enhance the plasticity of the materials. The enhanced cracking under cathodic polarization clearly implies a role of hydrogen in SCC of nickel alloys in primary water. However, as shown by Totsuka and Szklarska-Smialowska [39, 43], the hydrogen content is not higher under a cathodic potential than at $\mathrm{E}_{\text {corr }}$. Moreover, it has been shown difficult to induce embrittlement of Alloy 600 in primary water when straining at intermediate range after sufficient cathodic charging at $360^{\circ} \mathrm{C}$. The absorption of hydrogen under these conditions still needs more experimental support. 


\subsection{Corrosion Enhanced Plasticity}

Rios et al [60] and Magnin et al [50, 5B proposed a corrosion -enhanced plasticity model in order to account for the strong interactions between corrosion and local crack tip plastic conditions and the experimental evidence of an elementary cracking event at the scale of $1 \mu \mathrm{m}$. It is based on a local softening at the very crack tip and on the formation of a dislocation pile-up on a microstructural obstacle at some distance from the crack tip. It takes account of the generation of vacancies and hydrogen due to localized anodic dissolution and cathodic reactions at crack tips. The successive stages of the model are summarized in [53]. Any factor that enhances the local plasticity at crack tip will enhance the susceptibility of materials to SCC. Experimentally, SCC of Alloy 600 in primary water is predominantly of intergranular and discontinuous in nature. To further confirm the model, more crystallographic orientation related work needs to be done, particularly on precipitation-free single crystalline nickel alloys where the only possible obstacles are dislocation junctions or tangles.

\subsection{Internal Oxidation}

The internal oxidation mechanism is linked to oxygen penetration at the grain boundary and embrittlement may result either from $\mathrm{CO}_{2}$ bubbles, from the formation of a brittle intergranular oxide or from the presence of an oxygen film. The model predicts a strong dependence on the potential. When the potential is too low, oxidation is not possible while when it is too high, a compact oxide grows and prevents further oxygen diffusion and oxidation [55]. Therefore, according to the theory, cracking should only occur on a narrow range of potential near $\mathrm{Ni} / \mathrm{NiO}$ equilibrium. However, data showing an increased cracking growth rate at the potential well below the $\mathrm{Ni} / \mathrm{NiO}$ equilibrium potential, where the oxygen activity decreased, has been reported to disapprove the theory [20]. Moreover, the diffusion coefficient of oxygen is higher at grain boundary than in the bulk material. The internal oxidation should be localized at grain boundary. The observation of transgranular cracking on Alloy 600 in primary water indicates that grain boundaries are not necessary for crack propagation [53]. Therefore, at least the crack propagation mechanism does not involve an internal oxidation process.

\subsection{Creep Damage}

All proposed SCC mechanism involves plastic deformation. Parkins advocated that the synergistic effects of time-dependent corrosion reactions and microplastic strain explained why the strain rate, as opposed to the stress, often is the controlling parameter in determining whether or not cracking will occur [61]. Early in 1971, Lee and Vermilyea sought to examine the mechanical deformation of Alloy 600, recognizing that creep processes might contributing to intergranular stress corrosion cracking [62].

Attempts have been made to establish links between the strain rate, creep rate and IG fracture behavior $[56,57,58]$. Although the operating temperatures are relatively low on a homogeneous temperature scale, dislocation creep of nickel alloys at temperatures as low as $0.3 \mathrm{~T}_{\mathrm{m}}$ can be expected based on the deformation-mechanism map for $\mathrm{Ni}$ $20 \mathrm{Cr}$ alloy [63]. The effect of primary water on creep has been studied on industrial 
Alloy 600 and Alloy $690[56,58]$ and on controlled-purity nickel alloy with $16 \%$ chromium [54].

The consideration that creep might play an important role in IGSCC of nickel alloys in primary water is based on several experimental observations. These observations include: (1) cold work accelerated IGSCC, (2) increased chromium content was beneficial to IGSCC resistance, (3) grain boundary carbide precipitations were beneficial to IGSCC resistance, (4) the creep rate is comparable to IGSCC growth rate, (5) factors that enhance IGSCC such as small grain size, higher intragranular carbide precipitation, low grain boundary carbide coverage and cold work etc also enhance creep, (6) the intergranular fractured surface in Ar exhibited micro voids, a typical morphology of creep, (7) both IGSCC in primary water and diffusional creep are thermally activated processes and the activation energies for IG cracking and creep are comparable, and (8) both creep and primary water IGSCC are retarded by impurity segregation to grain boundary.

The creep damage mechanism proposed by Angeliu et al [54] considers the intergranular cracking as the result of creep void nucleation and growth at grain boundary. Studies on controlled purity nickel alloys supported this hypothesis and found that water is not necessary to induce IG cracking but could enhance it by increasing the dislocation mobility at the vicinity of grain boundary, probably through hydrogen.

\subsection{Grain Boundary Sliding (GBS)}

The presence of grain boundary sliding in mill-annealed and thermally treated Alloy 600 specimens [56] and the difficulties in correlating macroscopic creep rate with the observed IGSCC growth rate [40] led to the proposal that IG cracking could be explained in terms of the IG strain rate (GBS rate) rather than the macroscopic strain rate $[21,405 \Phi$. The amount of creep strain resulting from grain boundary cavitation (GBC), grain boundary sliding (GBS) and the matrix creep deformation can be determined for the material crept to failure under constant loading. The parameters required to calculate the sliding and cavitational strain can be obtained by using SEM as developed by Angeliu and Was [21].

Vaillant et al, by conducting a series of electrochemical tests and creep tests for Alloy 600 and Alloy 690 with a range of microstructures and mechanical properties in both $\mathrm{MA}$ and TT conditions in $360^{\circ} \mathrm{C}$ hydrogenated primary water, attempted to correlate the crack growth rate (da/dt) and the time-to-initiate cracking to the intergranular viscosity, $\eta$, assuming the model of viscous GBS applies [40]. According to the authors, the intergranular viscosity can be expressed as:

$$
\eta=\left(\frac{4 b \sigma}{\pi \dot{S}}\right)
$$


where $\sigma$ is the true stress and $2 \mathrm{~b}=5 \times 10^{-10} \mathrm{~m}$ is the thickness of the grain boundary. $\dot{S}$ is the GBS rate.

The contribution of GBS to the macroscopic creep strain, $\lambda$, defined as:

$$
\lambda=\frac{\varepsilon}{\varepsilon}=\frac{2 S}{\pi d \varepsilon}
$$

where $\mathrm{d}$ is the grain size, was investigated by Vaillant et al and was found to be a decreasing function of grain boundary coverage for Alloy 600 and Alloy 690 (MA and TT). The authors obtained that

$$
\lambda=\exp \left(\frac{-G B C}{h_{i}}\right)
$$

with the constant $h_{i}=0.04$ for Alloy 600 and $=0.08$ for Alloy 690 [40]. For same material, the authors found that $\lambda$ (the contribution of GBS to overall creep) was lower for TT materials than for MA materials. This is because TT decreases GBS but increases the macroscopic creep. A relationship between intergranular viscosity, $\eta$, creep parameter, $\mathrm{k}$, grain boundary coverage, GBC, grain size, $\mathrm{d}$, and materials constant $\mathrm{C}_{\mathrm{i}}$ was established as:

$$
\eta=C_{i} k^{-1} \times\left[\frac{\exp \left(\frac{G B C}{h_{i}}\right)}{d}\right]
$$

\subsection{Correlation between creep, GBS and SCC}

Attempts have been made to correlate the SCC susceptibility and creep rate in at least some metallurgical conditions [54,64]. These authors reported that the creep of the nickel alloys in primary water could be enhanced by a factor of $2-10$ and attributed this enhancement to the introduction of vacancies and/or hydrogen into the materials. Several studies have shown the significance of grain boundary sliding (GBS) in typical creep testing $[54,65,66]$. Thermal treatment at $700^{\circ} \mathrm{C}$ has been shown to decrease GBS probably by increasing the amount of grain boundary carbide. Kergaravat et al showed, by using CERT method, a correlation between GBS and SCC susceptibility of solutionannealed Alloy 600 and Alloy 690 [66].

The primary water slightly decreased the contribution of strain, for high purity $16 \% \mathrm{Cr}$ nickel alloy, due to GBS in the total deformation but did not reduced the GBS rate [54. 
Noel et al performed creep tests for Alloys 600 and 690 in primary water in order to establish a correlation between the creep behavior and SCC susceptibility of the materials [20]. An empirical relationship between the macroscopic strain, yield stress, creep factor $(\mathrm{k})$ and time $(\mathrm{t})$ was developed as:

$$
\dot{\varepsilon}=k\left(\frac{\sigma-Y S}{Y S}\right)^{0.86} \times t^{-0.47} \times \exp \left(-\frac{180,000}{R T}\right)
$$

The effects of intergranular carbides and intragranular carbides on creep behavior were identified [20]. For Alloy 600 in both MA and TT conditions, generally the higher the intergranular carbide precipitation, the higher the creep rate. The intragranular carbide precipitation was also found detrimental to creep resistance. It was also found that the thermal treatment at $700^{\circ} \mathrm{C}$ increased the susceptibility of Alloy 600 to creep by an order of magnitude. Comparing Alloy 690 and Alloy 600, it was found that for a given carbide precipitation, the creep factor, $\mathrm{k}$, is generally lower for Alloy 690 TT than for Alloy 600. A correlation was found valid between the time to cracking for RUB testing and the creep factor, $\mathrm{k}$ for Alloy $600 \mathrm{MA}$, i.e. the higher the creep rate, the higher the SCC susceptibility. However, the correlation did not hold for Alloy 600 TT. Between 325 to $400^{\circ} \mathrm{C}$, the activation energy for creep was found to be $180 \mathrm{~kJ} \mathrm{~mol}^{-1}$ for Alloy 600 under $650 \mathrm{MPa}$, which was believed in the range of the accepted activation energy of SCC $\left(30 \sim 45 \mathrm{kcal} \mathrm{mol}^{-1}\right.$ or $\left.130 \sim 190 \mathrm{~kJ} \mathrm{~mol}^{-1}\right)$. The attempt to correlate creep factor to SCC time to failure in RUB tests only led to marginal success.

Yi et al conducted the constant load creep tests on Alloy 600 (MA), a low carbon alloy A600LC, and two precipitation strengthened alloys, 625 and X-750 in hydrogenated water from $337 \sim 360^{\circ} \mathrm{C}$ [67]. The Alloy 600 was mill annealed at $1100^{\circ} \mathrm{C}$ and cooled in air, resulting in discrete carbides precipitated on grain boundary and in the matrix. The room temperature $\mathrm{pH}$ of the test solution was $10.1 \sim 10.3$. The hydrogen overpressure used was $20 \sim 25 \mathrm{psi}\left(40 \sim 60 \mathrm{cc} \mathrm{H}_{2} / \mathrm{kg} \mathrm{H}_{2} \mathrm{O}\right)$. The stress dependence of creep in Alloy $600 \mathrm{MA}$ in $337^{\circ}$ and $360^{\circ} \mathrm{C}$ primary water was clearly shown. As temperature increased from $337^{\circ}$ to $360^{\circ} \mathrm{C}$, the average creep rate increased by a factor of $3 \sim 10$. Over the temperature range from $337^{\circ}$ to $360^{\circ} \mathrm{C}$ and a stress range from 84 to $87 \mathrm{psi}$, the activation energy for creep of Alloy $600 \mathrm{MA}$ was found to be $64.6 \mathrm{kcal} / \mathrm{mol}$. The high activation energy and stress exponent of the power law relationship for creep of Alloy $600 \mathrm{MA}$ in high temperature water indicates that a dominant creep mechanism for Alloy $600 \mathrm{MA}$ in high temperature primary water should be climb-controlled dislocation creep [12, 67].

Attempts made to correlate creep and IGSCC of nickel alloys in high temperature water are not unanimously successful [18, 20, 40 67]. While Angeliu et al showed, for Inconel 600 type alloys, a strong correlation between IGSCC susceptibility using CERT tests in water and the steady-state creep rate in air [18], Boursier et al found that the correlation between creep and IGSCC was not clear for commercial alloys [64]. Yi et al, based upon the fractographic examinations, suggested that intergranular cracking of Alloy 600 be possibly induced by creep, following the processes that the 
intergranular cracking is initiated at the surface and propagated into the bulk of the specimens. The growth of the IG cracks induced by creep results in a rapid local reduction of cross-section area of the specimen, which increases the true stress [67]. When the true stress exceeds the UTS of the material, necking begins and the specimen fails [67].

In the work of Vaillant et al on Alloy 600 and Alloy 690 in $360^{\circ} \mathrm{C}$ hydrogenated primary water [40], a relationship between the time-to-initiate crack as measured by RUB specimen and the intergranular viscosity $(\eta)$ as calculated from GBC, grain size and macroscopic creep parameter, $\mathrm{k}$, was established for Alloy 600 as:

$$
t_{\text {init }}=3.07 \times 10^{-2} \eta^{0.57}
$$

No relationship was established for Alloy 690 since Alloy 690 did not crack as tested by RUB specimens. The authors concluded that GBS was not the most significant parameter to describe the initiation of SCC of nickel alloys [40].

However, a strong correlation between crack growth rate, da/dt, as obtained from CERT tests, and the intergranular viscosity, $\eta$, was established for both Alloy 600 and Alloy 690 in both MA and TT conditions [40]:

$$
\frac{d a}{d t}=5.71 \times 10^{4} \eta^{-0.76}
$$

As GBS (or $1 / \eta$ ) was decreased by high GBC and increased by creep factor $k$, the slow crack growth rate as obtained by CERT changed correspondingly.

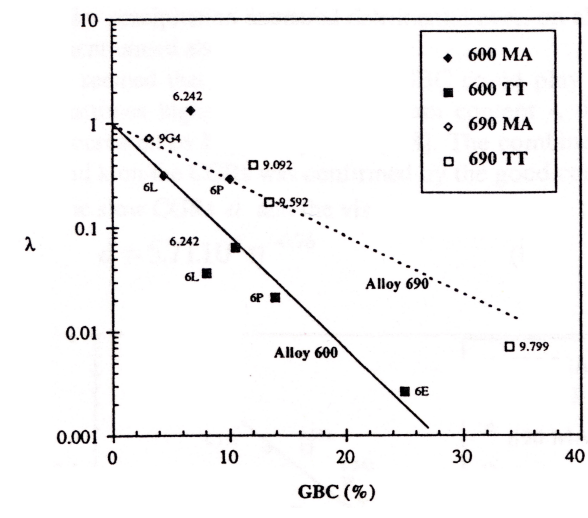

(a)

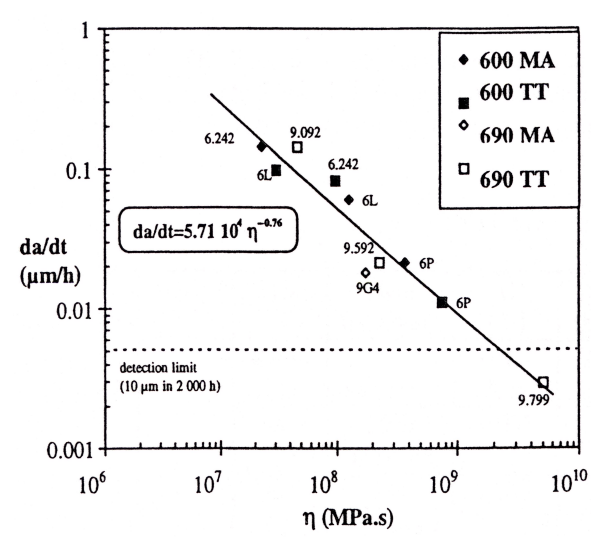

(b)

Figure 2 The contribution of GBS to creep strain $(\lambda)$ as a function of grain boundary coverage (GBC) (a) and the correlation between the slow crack growth rate in PWSCC (by CERT) at $360^{\circ} \mathrm{C}$ and the grain boundary viscosity, $\eta$ (b) [40] 
Figure 2 (a) and (b) show the GBS contribution to creep strain $(\lambda)$ as a function of the grain boundary coverage (GBC) and the correlation between IGSCC growth rate (da/dt) and intergranular viscosity $(\eta)(b)$, respectively, for Alloy 600 (MA and TT) and Alloy 690 (MA and TT) obtained by the method developed by Vaillant et al [40].

\section{Concluding remarks}

The lack of understanding of the IGSCC mechanism is due to a complex interaction of numerous variables such as microstructure, thermomechanical processing, strain rate, water chemistry and electrochemical potential. Hydrogen plays an important role in all these variables which individually or synergistically affect the susceptibility of Alloys 600 and 690 to IGSCC. This complexity significantly hinders a clearer and more fundamental understanding of the mechanism by which hydrogen promotes IGSCC. It is apparent that after more than 40 intensive years of laboratory testing, observations of tubing removed from operating steam generators and in-plant monitoring of crack propagation we still cannot tell the actual mechanism by which hydrogen interacts with the microstructure of the alloy and its correlation to plastic deformation mechanisms.

\section{Acknowledgement}

The work of FHH in preparing this manuscript was performed at former McDermott Technology, Inc. (MTI) which ceased operation in Dec. 2002. The content of this paper is not relevant to FHH's current assignment at BSC.

\section{Reference}

[1] R. B. Rebak and Z. Szklarska-Smialowska, "The Mechanism of Stress Corrosion Cracking of Alloy 600 in High Temperature Water”, Corr. Sci., 38, 971-988, 1996.

"Effect of Partial Pressure of Hydrogen on IGSCC of Alloy 600 in PWR Primary Water", Corrosion Vol. 47, No. 10, pp.754-757, 1991.

[2] R. W. Staehle and J. A. Gorman, "Quantitative Assessment of Submodes of Stress Corrosion Cracking on the Secondary Side of Steam Generator Tubing in Pressurized Water Reactors: Part 1", Corrosion, 59, 931 (2003) and Corrosion, 60, 5 (2004).

[3 ] T. M. Angeliu and G. S. Was, "Grain Boundary Chemistry and Precipitation in Controlled Purity Alloy 690", $4^{\text {th }}$ International Symposium on Environmental Degradation of Materials in Nuclear Power Systems - Water Reactors, Jekyll Island, GA, 1989, p. 5-64.

[4] G.S. Was, "Grain Boundary Chemistry and Intergranular Fracture in Austenitic Nickel-Base Alloys - A Review”, Corrosion, Vol. 4, No. 46, 1990, pp.319-330.

[5 ] G. S. Was and R. M. Kruger, Acta Metall., 33 (1985), p. 841.

[6 ] S. M. Bruemmer and C. H. Henager, Jr., Proc. 2nd Int. Symp. On Environmental Degradation of Materials in Nuclear Power Systems - Water Reactors, NACE, Houston, TX, p. 293, September 1985.

[7 ] J. Hertzberg and G. Was, "Isolation of Carbon and Grain Boundary Effects on the Creep and Intergranular Stress Corrosion Cracking Behavior of Ni-16Cr-9Fe in 360oC Primary Water", Metallurgical and Materials Transaction A, 29A (1998), pp. 1035-1046.

[8] J. A. Gorman, E. S. Hunt, and A. R. Mcllree, Proc. 2nd Int. Symp. On Environmental Degradation of Materials in Nuclear Power Systems - Water Reactors, NACE, Houston, TX, p. $557,1985$. 
[9] P. Saint Paul, "Laboratory Investigation of Alloy 600 in SCC in High Temperature Water", Proc. 1985 Workshop on Primary Side SCC of PWR Steam generator Tubing, EPRI NP-5158, San Diego, CA, March 20-22, 1985.

[10] N. Totuska, E. Lumarska, G. Gragnolino and and Z. Szklarska-Smialowska, Corrosion 43 (1987), p. 505.

[11] J. K. Sung and G. S. Was, "The Role of Grain Boundary Chemistry in Pure water Intergranular Stress Corrosion Cracking of Ni-16Cr-9Fe Alloys", Fourth Symposium on Environmental Degradation of Materials in Nuclear Power Systems - Water Reactors, Jekyll Island, GA, 1989, p. 6-25.

[12] R. W. Evans and B. Wilshire, Creep of Metals and Alloys, The Institute of Metals, London (1985).

[13 ] G. Economy, R. J. Jacko, J. A. Begley and F.W. Pement, Corrosion 43 (1987), p. 727.

[14] R. L. Cowan II, and C. S. Tedmon Jr., Advance in Corrosion Science and Technology, Plenum Press, New York, NY, 1973, p. 293.

[15] D. M. Symons, "The Effect of Carbide Precipitation on the Hydrogen-Enhanced Fracture Behavior of Alloy 690", Metallurgical and Materials Transactions A (USA), Vol. 29A, No. 4, pp. 1265-1277 A, April 1998.

[16] S.H. Goods and L.M. Brown, Acta Metall. 27 (1979), pp. 1-15.

[17] G. A. Young and J. R. Scully, Scripta Mater., 36 (1997), pp. 713-719.

[18] T. M. Angeliu, J. K. Sung and G. S. Was, "The Role of Carbon and Chromium on the Mechanical and Oxidation Behavior of Nickel-Base Alloys in High Temperature Water", $5^{\text {th }}$ International Symposium on Environmental Degradation of Materials in Nuclear Power Systems - Water Reactors, Monterey, CA, USA, August 25-29, 1991, p. 475.

[19] J. R. Donati, M. Guttmann, Y. Rouillon, P. Saint-Paul and J. C. Van Duysen, "Stress Corrosion Cracking Behavior of Nickel Base Alloys with 19\% Chromium in High Temeprature Water", $3^{\text {rd }}$ International Symposium on Environmental Degradation of Materials in Nuclear Power Systems - Water, Traverse City, Michigan, 1997. Pp. 697-701.

[20] D. Noel, O. De Bouvier, F. Foct, T. Mignin, J. D. Mithieux and F. Vaillant, "Study of the Mechanisms of Stress Corrosion Cracking of Alloys600 and 690 in Primary Water Reactor Conditons", Second International Conference on Corrosion-Deformation Interactions, CDI'96, Nice, France, 24-26 Sept. 1996.

[21] T. M. Angeliu, D. J. Paraventi and G. S. Was, Corrosion, 51, (1995), 837-848.

[22] G. Sui, G. B. Heys and J. Congleton, "Stress Corrosion Cracking of Alloy 600 and Alloy 690 in Hydrogen/Steam and PWR Primary Side Water", 8th Symposium on environmental Degradation of Materials in Nuclear Power Systems - Water Reactors, Amelia Island, FL, August 10-14, 1997, pp. 274-281.

[23] G. Sui, J. M. Titchmarsh, G. B. Heys and J. Congleton, "Stress Corrosion Cracking of Alloy 600 and Alloy 690 in Hydrogen/Steam at 380'C", Corros. Sci. 39 (1997), pp. 565-587.

[24] K. Norring, K. Stiller and J-O, Nilsson, "Grain Boundary Microstructure, Chemistry, and IGSCC in Alloy 600 and Alloy 690", 5 $5^{\text {th }}$ International Symposium on Environmental Degradation of Materials in Nuclear Power Systems - Water Reactors, Monterey, CA, August 25-29, 1991, pp. 482-487.

[25] M. T. Miglin and H. A. Domain, Corrosion of Nickel Alloys, ed. R.C. Scarberry, Materials Park, OH: ASMInternational, 1985, p. 147.

[26] C. A. Grove and L. D. Petzold, Corrosion of Nickel Alloys, ed. R.C. Scarberry, Materials Park, OH: ASM International, 1985, p.165.

[27] G. P. Airey, Corrosion 35 (1979), p. 129.

[28] M. Cornet, C. Bertrant and M. Da Cunha, Metall. Trans. A. 13A (1982), p.141.

[29] P.G. Caceres, B. Ralph, G.C. Allen, and R.K. Wild, Phil. Mag. A. 59, 6(1989): p. 1119.

[30] P.G. Caceres, B. Ralph, G.C. Allen, and R.K. Wild, Phil. Mag. A. 59, 6(1989): p. 1137.

[31] P. Berge, 3rd International Symposium on Environmental Degradation of Materials in Nuclear Power Plant Systems - Water Reactors, TMS, Warrendale, PA, p. 49, 1988. 
[32] K. Stiller, J. Nilsson and K. Norring, Metall. Mater. Trans. A, 27A (1996), pp. 327-341.

[33] S. Yamaura, Y. Igarashi, S. Tsurakawa and T. Watanabe, "Structure-Dependent Intergranular Oxidation in Ni-Fe Polycrystalline Alloy”, Acta Materialia, 47 (1999), pp. 1163 1174.

[34] H. Liu, M. Gao, D. Harlow and R. Wei, " Grain Boundary Character and Crabide Size and Spatial Distribution in a ternary Nickel Alloy", Scripta Metallurgica et Materialia, 32 (1995), pp. 1807-1812.

[35] C. Cheung, U. Erb and G. Palumbo, "Applications of Grain Boundary Engineering Concepts to Alleviate Intergranular Cracking in Alloy 600 and Alloy 690", Materials Science and Engineering, A, 185 (1994), pp. 39-43.

[36] D. Crawford, "The Effect of Grain Boundary Misorientation on the Intergranular Cracking Behavior of Ni-16Cr-9Fe in $360^{\circ} \mathrm{C}$ Argon and High Purity Water", Ph.D Thesis, University of Michigan, 1991.

[37] V. Thaveeprungsiporn and G. Was, "The Role of Coincidence-Site-Lattice Boundaries in Creep of Ni-16Cr-9F $\mathrm{F}^{\mathrm{e}}$ at $360^{\circ} \mathrm{C}$ ", Metallurgical and Materials Transactions, A, 28A (1997), pp. 2101-2112.

[38] T. Cassagne, B. Fleury, F. Vaillant, O. de Bouvier, and P. Combrade, "An Update on the Influence of Hydrogen on the PWSCC of Nickel Base Alloys in High Temperature Water", $8^{\text {th }}$ International Symposium on Environmental Degradation of Materials in Nuclear Power Systems - Water Reactors, Amelia Island, FL, August 10-14, 1997, pp. 307-315.

[39] N. Totuska and Z. Szklarska-Smialowska, "Effect of Electrode Potential on the HydrogenInduced IDSCC of Alloy 600 in Aqueous Solution at 350'C", Corrosion 43, 124 (1987), pp. 734.

[40] F. Vaillant, J. D. Mithieux, O. de Bouvier, D. Vancon, G. Zacharie, Y. Brechet and F. Louchet, "Influence of Chromium Content and Microstructure on Creep and PWSCC Resistance of Nickel Base Alloys", $9^{\text {th }}$ International Symposium on Environmental Degradation of Materials in Nuclear Power Systems - Water Reactors, Newport Beach, CA., 1999.

[41] N. Totuska, E. Lunarska, G. Gragnolino and and Z. Szklarska-Smialowska, Scripta Metall., 20 (1986), p. 1035.

[42] N. Totuska, Corrosion 44, (1988), pp. 124

[43] N. Totuska and Z. Szklarska-Smialowska, Scr. Metall. 21, (1987), p. 45.

[44] R. S. Pathania and A. R. McIlree, "A Review of the Effect of Hydrogen on Stress Corrosion Cracking of Alloy 600 in 360oC Water", Third International Symposium on Environmental Degradation of Materials in Nuclear Power Systems - Water Reactors, Warrendale, PA, TMSAIME, 1988, p. 551.

[45] K. Norring, J. Engstrom and P. Norberg, "Intergranular Stress Corrosion Cracking in Steam generator Tubing, Testing of Alloy 600 and Alloy 600 Tubes", Third International Symposium on Environmental Degradation of Materials in Nuclear Power Systems - Water Reactors, Traverse City, Michigan, TMS-AIME, 1987, p. 587.

[46] K. Norring, J. Engstrom and H. Törnblom, "Intergranular Stress Corrosion Cracking of Steam generator Tubing, 25,000 Hours Testing of Alloy 600 and Alloy 690", Fourth Symposium on environmental Degradation of Materials in Nuclear Power Systems - Water Reactors, Jekyll Island, GA, 1989, p. 12-1.

[47] G.P. Airey, Proc. 1985 Workshop on Primary-Side Stress Corrosion Cracking of PWR Steam Generator Tubing, EPRI NP-5158, May, 197.

[48] G. Economy, R. J. Jacko, J. A. Begley and F.W. Pement, "Influence of Hydrogen Partial Pressure on the IGSCC Behavior of Alloy 600 Tubing in 360oC Water or 400oC Steam", Corrosion'87, NACE, Paper No. 92, March 9-13, 1987.

[49] "Stress Corrosion Cracking of Inconel Alloy 600 in High temperature Water - An Update", Corrosion 40 (1984), pp. 425.

[50] T. Magnin, A. Chambreuil, and B. Bayle, Acta. Met. Mater., 44 (1996), pp. 1457-1470

[51] T. B. Cox and J. R. Low, Metall. Trans. A, 5 (1974), pp. 1457-1470.

[52] J.C.M. Li, R. A. Oriani and L. S. Darken, Z. Phys. Chem. (NF), 49 (1966), pp. 271-290. 
[53] T. Magnin, F. Foct and O. de Bouvier, "Hydrogen Effects on PWR SCC Mechanisms in Monocrystalline and Polycrystalline Alloy 600", 9th International Symposium on Environmental Degradation of Materials in Nuclear Power Systems - Water Reactors, Newport Beach, CA, 1999.

[54] T. M. Angeliu, D. J. Paraventi and G. S. Was, Corrosion, 51, (1995), 837-848.

[55] P. Scott and M. Le Calvar, "Some Possible Mechanisms of Intergranular Stress Corrosion Cracking of Alloy 600 in PWR Primary Water", $6^{\text {th }}$ International Symposium on Environmental Degradation of Materials in Nuclear Power Systems - Water Reactors, San Diego, CA., 1-5 August, 1993.

[56] J. M. Gras, Proc. Parkins Symp. On Fundamental Aspects of Stress Corrosion Cracking, ED. TMS, 1992, pp. 411-432.

[57] T. M. Angeliu and G. S. Was, Metall. Trans. A, 25A (1994), pp. 1169-1183.

[58] J. M. Boursier, O. D. Bouvier, J. M. Gras, D. Noel, R. Rios, and F. Vaillant, CorrosionDeformation Interactions, CDI'92, ED. Les Editions de Physique, Les Ulis (France), 1993, pp. $117-139$

[59] G. S. Was, J. K. Sung and T. M. Angeliu, Metall. Trans. A, 23A (1992), pp. 3343-3359.

[60] R. Rios, T. Magnin, D. Noel and O. de Bouvier, Metal Trans. A, 26A (1995), pp. 925-939.

[61] R. N. Parkins, Corrosion, 46 (1990), pp. 178-189.

[62] D. Lee and D. A. Vermilyea, "The Initiation of Intergranular Failure in Inconel 600", Met. Trans. 2 (1971), pp. 2565-2571.

[63] H. J. Frost and M. F. Ashby, Deformation-Mechanism Maps, The Plasticity and Creep of Metals and Ceramics (Oxford, NY, Pergamon Press, 1982), p. 53.

[64] J. M. Boursier, D. Desjardines and F. Vaillant, Corros. Sci., 37 (1995), pp. 493-508.

[65] D. Garriga, J. M. Gras, Y. Rouillon, F. Vaillant, J. C. Van Duysen and G. Zacharie, Proc. Congr. On Life Prediction of Corrodible Structures, Cambridge, 1991, Paper No. 56.

[66] Kergaravat, X. Ballin and G. Robert, Second International Conference on CorrosionDeformation Interactions, CDI'96, Nice, France, 24-26 Sept. 1996.

[67] Y. Yi, G. S. Was, J. Cookson, J. S. Fish, S. A. Attanasio, H. T. Krasodomski and W.W. Wilkening, "Creep of Nickel Alloys in High Temperature Water", Proc. of $9^{\text {th }}$ International Symposium on Environmental Degradation of Materials in Nuclear Power Systems - Water Reactors, Newport Beach, CA, 1999. 